\title{
Normalization of disrupted clock gene expression in males with tetraplegia: a crossover randomized placebo-controlled trial of melatonin supplementation
}

\author{
Emil Kostovski $\mathbb{1}^{1,2} \cdot$ Elena Frigato ${ }^{3} \cdot$ Mladen Savikj $^{1,2} \cdot$ Anders $^{\text {Dahm }}{ }^{2,4,5} \cdot$ Per Morten Sandset $^{2,5}$.

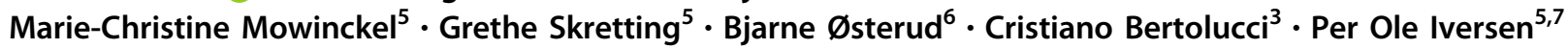

Received: 1 March 2018 / Revised: 2 June 2018 / Accepted: 18 June 2018 / Published online: 9 July 2018

(c) International Spinal Cord Society 2018

\begin{abstract}
Study design Crossover double blind, randomized placebo-controlled trial.

Objectives Circadian oscillators are located both in the brain and in peripheral organs. Melatonin, the main brain-derived hormone governing circadian variations, is highly associated with daylight patterns. However, in subjects with tetraplegia the melatonin levels are blunted. Here we studied peripheral oscillators in peripheral blood mononuclear cells (PBMCs) in males with tetraplegia by examining how exogenous melatonin may influence the expression of clock gene mRNAs.

Setting Sunnaas Rehabilitation Hospital, Nesoddtangen, Norway.

Methods Six males with tetraplegia received $2 \mathrm{mg}$ of melatonin or placebo 4 days before the study period. We also included six able-bodied men sleeping or kept awake during the night. Plasma samples were collected four times during a 24-h period. The mRNA expression levels of the clock genes PER1, PER2, BMAL1, and REV-ERB $\alpha$ were quantified in PBMCs using quantitative RT-PCR.

Results The mRNA expression levels of PER-1 and -2 and REV-ERB $\alpha$ were increased at 04:00 $\mathrm{h}$ compared with the ablebodied controls $(p<0.05)$. Melatonin supplementation changed mRNA peak-time toward the time of supplementation.

Conclusions Several peripheral clock genes displayed distorted expression levels in tetraplegia. Supplementation with melatonin changed the mRNA expression levels of these genes toward those observed among able-bodied.

Sponsorship Financial support was provided from the Throne Holst Foundation, Sunnaas Rehabilitation hospital and the University of Ferrara (FAR2016).
\end{abstract}

Electronic supplementary material The online version of this article (https://doi.org/10.1038/s41393-018-0176-x) contains supplementary material, which is available to authorized users.

Emil Kostovski

Emil.Kostovski@sunnaas.no

1 Department of Research, Sunnaas Rehabilitation Hospital, Nesoddtangen, Norway

2 Faculty of Medicine, University of Oslo, Oslo, Norway

3 Department of Life Sciences and Biotechnology, University of Ferrara, Ferrara, Italy

4 Department of Haematology, Akershus University Hospital, Lørenskog, Norway

5 Department of Haematology, Oslo University Hospital, Oslo, Norway

6 Faculty of Medicine, University of Troms $\varnothing$, Troms $\varnothing$, Norway

7 Department of Nutrition, IMB, University of Oslo, Oslo, Norway

\section{Introduction}

In all species many biochemical, physiological, and behavioral processes oscillate with a 24-h period. These rhythms are driven by endogenous circadian clocks, which function through interacting with positive and negative transcriptional/ translational feedback loops. The main murine genes of the negative-feedback loop are the Pers and Crys, whereas Clock and Bmall, coding for two basic helix-loop-helix transcriptional activators, are important genes of the positive loop [1]. These positive and negative feedback loops are interconnected by a second loop where the transcription of $R e v-E r b \alpha$ and Rora, two nuclear orphan receptor genes, is regulated by Clock:Bmall heterodimers. Rev-Erb $\alpha$ and Rora compete for the same element on the Bmall promoter, but have opposing actions. This circadian timing system is governed by a master circadian pacemaker, located in the suprachiasmatic nucleus of the anterior hypothalamus, as well 
a Placebo or Circadin $2 \mathrm{mg}$ Blood sample Darkness/sleep

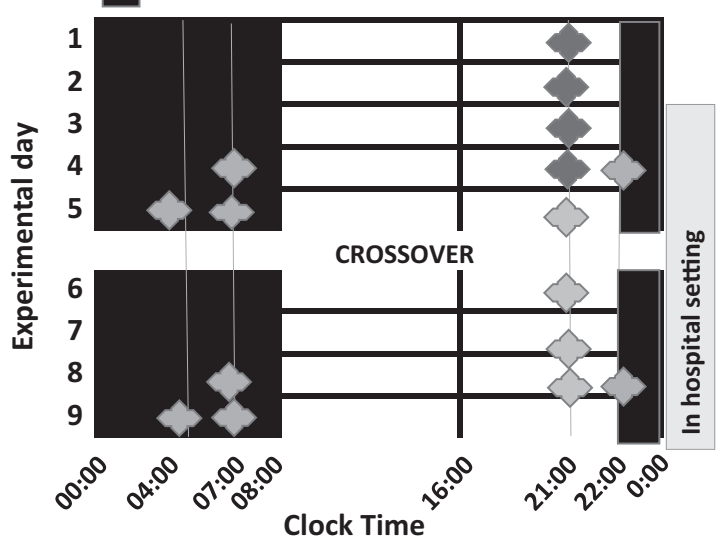

b

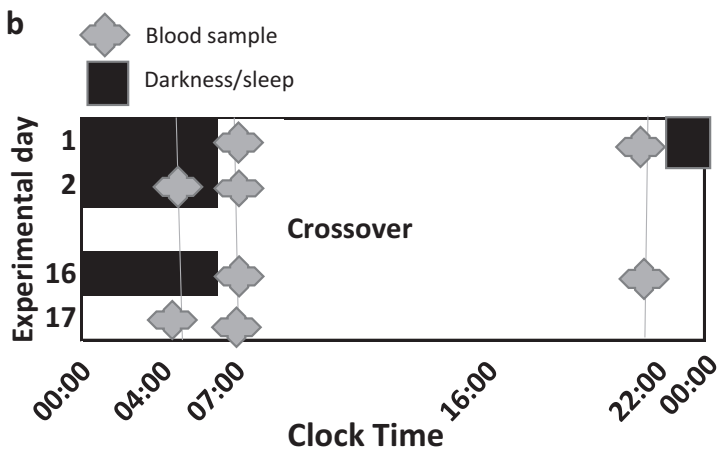

Fig. 1 a Experimental protocol, males with tetraplegia. Blood samples, collected four times over a continuous $24 \mathrm{~h}$ period beginning on experimental day 4 and 8, were assayed for their melatonin concentration and for the expression of clock genes in PBMCs. Crossover from placebo or melatonin were scheduled to experimental day 5 . At the start of the study, participants lived on their habitual sleep/wake schedule. Wake episodes were spent in normal indoor light intensities, and sleep episodes took place in darkness. b Experimental protocol, able-bodied males. Blood samples, collected four times over a continuous $24 \mathrm{~h}$ period beginning on experimental day 1 and 16 (with a 14 days crossover time) were assayed for their melatonin concentration and for the expression of clock genes in PBMCs. At the start of the study, participants lived on their habitual sleep/wake schedule. Wake episodes were spent in normal indoor light intensities, and sleep episodes took place in darkness

as peripheral oscillators located in most organs and tissues [2]. Also in humans the expression of PER1, PER2, and BMAL1 mRNAs show circadian rhythmicity in peripheral tissues (e.g., the skin and the oral mucosa), and in the peripheral blood mononuclear cells [PBMCs] [3-6].

Following a complete cervical spinal cord injury (SCI) in humans, nervous input through somatic and autonomic afferent fibers from the body below the SCI level is disrupted and the efferent sympathetic innervation of the pineal gland via the superior cervical ganglion is lacking control from higher autonomic centers. It has been hypothesized that these disrupted nervous connections abolish rhythmic melatonin production. In line with this, we and others have reported blunted circadian rhythm and low blood levels of melatonin in persons with cervical SCI [7-9], and indeed, in healthy adults, melatonin levels range from $\sim 10 \mathrm{pg} / \mathrm{mL}$ at the end of the light period up to $200 \mathrm{pg} / \mathrm{mL}$ near the midpoint of the dark period, whereas in tetraplegic subjects the corresponding values are closer to 2 and $15 \mathrm{pg} / \mathrm{mL}$.

Melatonin has been used as a marker of the central circadian pacemaker in humans [10, 11]; however, it is unclear how the peripheral oscillators are influenced by the absence of melatonin rhythmicity in humans with complete cervical SCI and blunted melatonin levels. To study the effect of melatonin on the circadian variations of markers of hemostasis (many of which show 24-h rhythms [7 and references therein]), we performed a cross-over double-blind, randomized placebo-controlled trial of melatonin supplementation in tetraplegia [7]. We could not attribute any major role of melatonin in regulating the circadian variation of a wide range of hemostatic factors [7]. However, in a previous investigation we did find melatonin to reduce peak thrombin generation [12]. Although melatonin supplementation did not change the levels of many other hemostatic factors, it could modify circadian variations of peripheral clock genes. We therefore planned for and used specially prepared blood samples (PAX gene RNA Blood collection tubes (PreAnalytiX) obtained in our randomized trial to examine the effect of melatonin supplementation on the expression of four cardinal circadian clock genes (Perl, Per2, Bmall, and RevErb $\alpha$ ), in PBMCs sampled four times throughout a 24-h cycle in six tetraplegic subjects. Blood was specifically collected four times during a 24-h period, namely at 07:00, 22:00, 04:00, and 07:00 h, to capture possible changes in clock gene expression levels around the time of melatonin supplementation. We also included six able-bodied subjects sleeping or kept awake during the night as controls.

\section{Methods}

\section{Subjects and design of study}

The study was approved by the Regional Committee for Medical Health Research Ethics in Norway and is registered with Clinicaltrials.gov identifier: NCT 01741389 and with the Norwegian Medicines Agency EUDRACT no. 2010021212-24. Details of the study design and randomization have been described previously [7]. Briefly, we designed a cross-over double-blind, placebo-controlled trial of six tetraplegic men in addition to a control group of six ablebodied men, i.e., four study-groups: tetraplegic men given placebo, the same tetraplegic men given melatonin, and able-bodied men sleeping or kept awake during the night. During the time of the trial sunrise and sunset occurred 
around 07:00 and 19:00 h, respectively. The trial was performed in the south of Norway. The tetraplegic men were invited through the hospital's own in-patient coordinator. The able-bodied participants were all hospital staff and were invited through intranet or by direct request. The tetraplegic men were randomized to first receive $2 \mathrm{mg}$ of melatonin (Circadin; Neurim Pharmaceuticals, Zug, Switzerland) or placebo (Kragerø Tablettproduksjon AS, Kragerø, Norway) daily at 22:00 h for 4 days before they were subjected to a 24-h period of blood sampling (see Fig. 1a). The dose of 2 $\mathrm{mg}$ of melatonin is recommended for the treatment of insomnia, and in a pilot study we found that this dose markedly increased the blood concentration of melatonin (data not published). Blood was collected four times during a 24-h period, namely at 07:00, 22:00, 04:00, and 07:00 h. The "wash-out" period lasted 4 days in the tetraplegic group before the cross-over, which is assumed to be sufficient since the half-life of melatonin is about $35-50 \mathrm{~min}$, thus ensuring minimal, if any, carry-over effect. The able-bodied men were subjected to a similar two 24-h periods of blood sampling, with 2 weeks in-between sampling. They slept or were kept awake during the night with group-common lowintensity activities such as playing computer games, table tennis or watching movies (see Fig. 1b). All the participants received standardized meals at regular time-points. No other restrictions except zero alcohol intake and maximum two cups of coffee were required from the participants.

\section{Blood sampling}

Venous blood samples were collected in $5 \mathrm{ml}$ Vacutainer vacuum tubes containing $0.5 \mathrm{ml}$ buffered sodium citrate $(0.129 \mathrm{M})$ (Becton-Dickinson, Plymouth, UK) and $2.5 \mathrm{ml}$ PAX gene RNA Blood collection tubes (PreAnalytiX, Hombrechtikon, Switzerland). Citrated blood was kept at room temperature and immediately centrifuged at $2000 \mathrm{~g}$ for 15 min. Platelet-poor plasma aliquots and PAX gene RNA tubes were stored at $-70{ }^{\circ} \mathrm{C}$ until assayed. All analyses were performed examiner-blind, and the samples were run in-batch using a balanced set-up with equal number of cases and controls in each run.

\section{Assays}

Melatonin concentrations were assayed with an ELISA-kit (Buhlmann Lab. AG, Basel, Switzerland) as described earlier [7]. For clock gene expression analysis, DNasetreated total RNA was isolated from PBMCs and used for cDNA synthesis (iScript ${ }^{\mathrm{TM}}$ cDNA synthesis kit, Biorad, Milan, Italy). cDNA was PCR-amplified in a CFX Connect Real-Time PCR Detection System [Biorad, Milan, Italy] using SsoFast EvaGreen Supermix (Biorad). The following primers were used:
Perl F: GTGCGGAGGACACTCCTG, R: TTGGCTGA GGGAGTGAGGT;

Per2 F: TCGTTTGAACTGCGGTGAC, R: GTATCC ATTCATGCTGGGCT;

Bmall F: AGCCACGGTGGTGCTGGCTA, R: AACCA ATGAAGGCCCAGGATTCCAC;

Rev-Erbo: F: CGCAACCTCTAGTTTGAGTCAAGGT CC, R: ACGCCACCTGTGTTGTTGTTGGA;

18S rRNA F: CGAGCCGCCTGGATACC, R: CATGGC CTCAGTTCCGAAAA;

GAPDH F: GATGACATCAAGAAGGTGGTGAAGC, R: TTCGTTGTCATACCAGGAAATGAGC;

CDK4 F: ATCCCAATGTTGTCCGGCTG, R: TGATC TCCCGGTCAGTTCGG.

We used NormFinder (Aarhus University Hospital, Denmark) to evaluate and screen the following three housekeeping genes: GAPDH, CDK4, and $18 S$ rRNA. Based on the rankings, we have chosen to normalize to the geometric mean of CDK4 and 18S, and the expression of genes of interest using the $2^{-\Delta \Delta C t}$ method (arbitrary units (AU)) [13]. We furthermore scaled the AU values to the mean overall expression of each respective gene for every patient and time point. This allowed us to plot expression of several genes on the same graph in order to visualize the daily cycle of genes relative to their own expression level.

\section{Statistics}

The statistical analyses were performed with SPSS version 25.0 (Chicago, IL, USA) and the MedCalc Software (Mariakierke, Belgium). Values are given as mean absolute values with standard error of the mean (SEM) or as median (range), as appropriate. Differences in the plasma concentrations of the various parameters between the study groups were evaluated with two-ways ANOVA and Dunnett post hoc test, profile differences were evaluated with mixed models (time (continuous) versus group (categorical)). We considered $p$-values less than 0.05 to indicate statistical significance.

\section{Results}

\section{Characteristics of the study participants}

The mean (range) age of the males with tetraplegia was 46 (27-60) years. Their injury level ranged from cervical vertebra 5 to 8 , all diagnosed with a complete injury according to the American Spinal Cord Injury Association International Standards For Neurological Classification of SCI [14], and the mean (range) time since injury was 18 (3-43) years. Their mean (range) body mass index (BMI) value was $25.4(23.8-26.6) \mathrm{kg} / \mathrm{m}^{2}$. The corresponding values among the controls were not significantly different 
from the tetraplegic men; age 43 (34-54) years and BMI $26.6(20.1-35.3) \mathrm{kg} / \mathrm{m}^{2}$. All participants completed the study protocol except for one male with tetraplegia who withdrew from one of two 24-h blood samplings.

\section{Plasma melatonin profiles in the two study groups}

Figure 2 shows the 24-h plasma melatonin levels in the four study groups. The plasma melatonin levels among the ablebodied increased in the evening $(22: 00 \mathrm{~h})$, irrespective of whether they slept or not. A similar pattern was observed upon melatonin supplementation to the tetraplegic group, where the night-time melatonin plasma levels were elevated about 50-fold. As expected, the plasma melatonin levels remained low and unaltered in the tetraplegic group given placebo.

\section{Disrupted PBMC clock-gene rhythmicity in tetraplegia}

To visualize the rhythmicity of genes and present the expression of core clock genes on a single graph for each group, mean scaling was performed and presented in Fig. 3. Only the sleeping able-bodied group had a visual diurnal rhythmicity, i.e., the two 07:00 $\mathrm{h}$ measurement-points being similar for each of the four clock gene expression levels. In contrast, when these able-bodied were awake they had slightly downward flattened profiles for the four clock gene

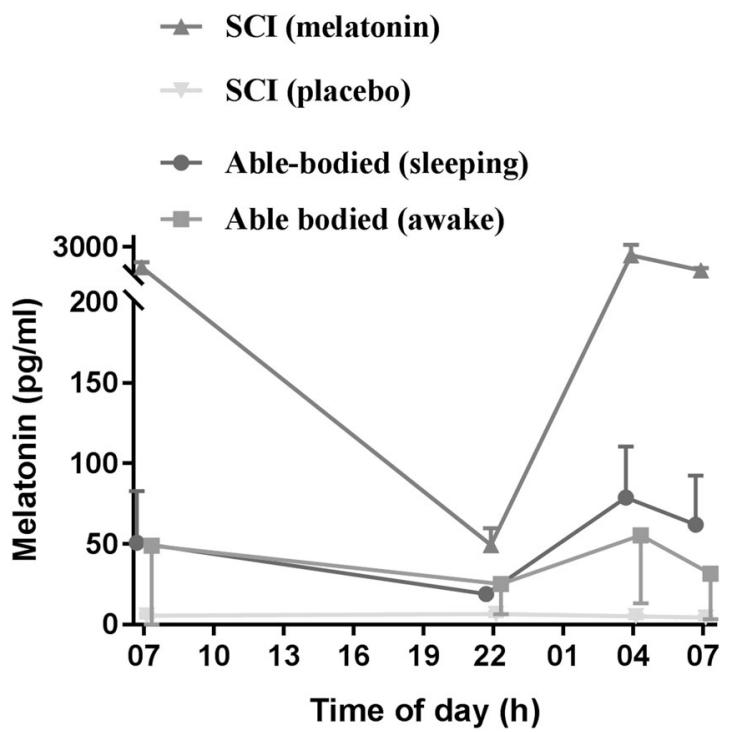

Fig. 2 Plasma melatonin concentrations ( $\mathrm{pg} / \mathrm{ml})$ in the four study groups during the 24-h observation period. Values are means (SEM). Melatonin or placebo were given orally to the tetraplegia group every night at 22:00 $\mathrm{h}$ for four continuous days before blood sampling. Melatonin was measured at 07:00, 22:00, 04:00, and 07:00 h during the 24-h observation period. The able-bodied males slept (from 23:00 to $07: 00 \mathrm{~h}$ ) or were kept awake during the 24 -h observation period. SCI spinal cord injured expression levels. The maximum mRNA expression level for the sleeping able-bodied apparently occurred at $07: 00 \mathrm{~h}$ for Perl, Per2, and Bmall, whereas the mRNA for Rev$E r b \alpha$ had a maximum at 22:00 h. In the tetraplegic group the maximum mRNA expression level of all four clockgenes apparently occurred at $22: 00 \mathrm{~h}$ in the melatoninsupplemented and at 04:00 h in the placebo-supplemented group. We examined the overall rhythm using mixed model (time versus group) analysis in the four study groups and found that the tetraplegia group receiving placebo had a different profile compared with the able-bodied group (awake) for BMAL1 and PER-1 expression ( $p=0.01$ and $p=0.002$, respectively). Males with tetraplegia receiving placebo had a different mRNA expression profile for all clock gene investigated than the same males receiving melatonin (Rev-Erbo: $p=0.001$, Bmall: $p=0.03$ Perl: $p=0.02$, Per $2: p=0.004$ ). There were no other significant differences in any of the other mRNA levels or profiles of the four clock genes among other study-group comparisons.

We next examined the mRNA expression levels of the clock genes separately among the four study groups (Fig. 4). We observed increased Perl, Per2, and and RevErb $\alpha$ mRNA expression levels at 04:00 h in the tetraplegic group receiving placebo compared with sleeping ablebodied ( $p=0.04, p=0.03$, and $p=0.02$, respectively). However, the variation (SEM) of mRNA expression levels in both tetraplegic groups (placebo or melatonin) was large. The mRNA expression levels of BMAL1 remained unchanged $(p>0.05)$ among the four study groups.

\section{Discussion}

To our knowledge, this is the first study of mRNA expression levels of the clock genes Perl, Per2, Bmall, and Rev-Erbo in males with tetraplegia, a condition leading to disrupted efferent input to the pineal gland from the superior cervical ganglion and thus blunted plasma melatonin levels. Our results suggest disrupted peripheral clock regulation in males with cervical SCI. In line with this, we found that the tetraplegic groups receiving placebo had increased Per1, Per2, and Rev-Erb $\alpha$ expression levels at 04:00 h compared to awake able-bodied controls. Furthermore, the melatonin supplementation changed the expression profile in the tetraplegic group by changing the maximum value from 04:00 $\mathrm{h}$ to $22: 00 \mathrm{~h}$, i.e., toward the time point of supplementation of melatonin. Thus the males with SCI receiving melatonin behaved more like the ablebodied males staying awake overall, with lower expression of all clock genes measured at $07: 00 \mathrm{~h}$ in contrast to the able-bodied sleep group. This may be a result of clearance of melatonin in the SCI group related to the 50 times higher plasma levels of melatonin. 
a)

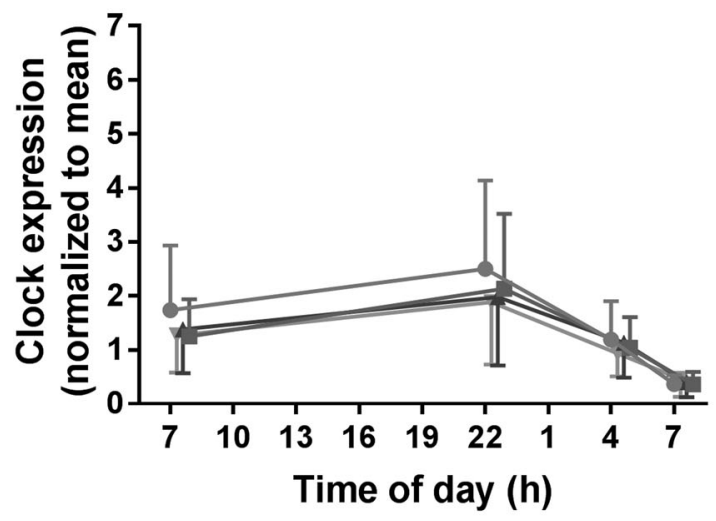

C)

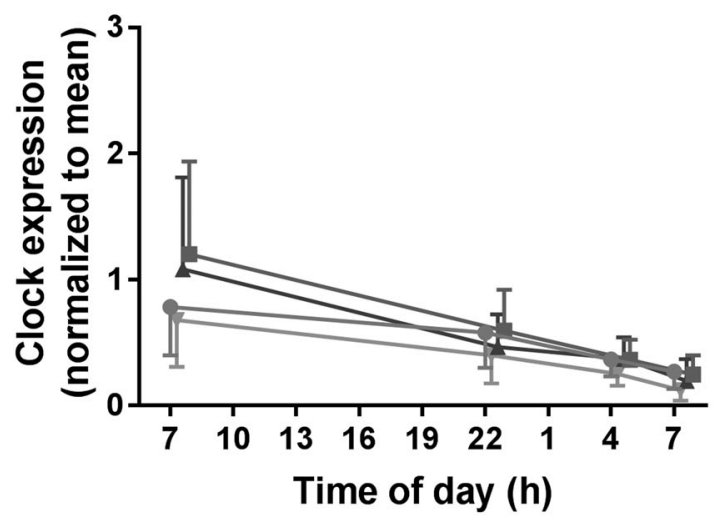

Fig. 3 Overall mRNA expression levels of the clock genes in PBMCs during the 24-h observation period. Values are means $( \pm$ SEM). The expression of a gene in each sample was scaled to a mean expression of the same gene in all samples (AU/AU $\mathrm{Aean})$ and presented as scaled AU units. a Spinal cord injured (melatonin); b Spinal cord injured (placebo); c Able-bodied males (awake); and d Able-bodied males

It is well known that in addition to the disrupted efferent input to the suprachiasmatic nucleus, tetraplegic subjects have a low-grade chronic inflammation [15]. Inflammation has been shown to disrupt the expression of clock genes [16]. Our results showing reduced clock-gene mRNA levels in some of the tetraplegic subjects are in accordance with other studies of PCBMs during ongoing inflammation and disease processes [17]. For example, patients with chronic lymphatic leukemia have significantly downregulated expression of both melatonin plasma levels and mRNA of clock genes in peripheral blood (Bmall, Perl, and Per2) [18]. Sleep deprivation also leads to decreased clock gene expression levels $[19,20]$, which we also found among some of our able-bodied study subjects. b)

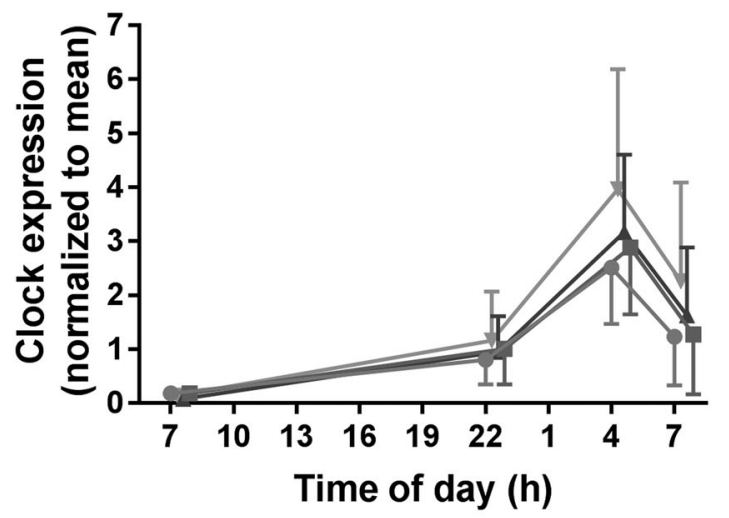

d)
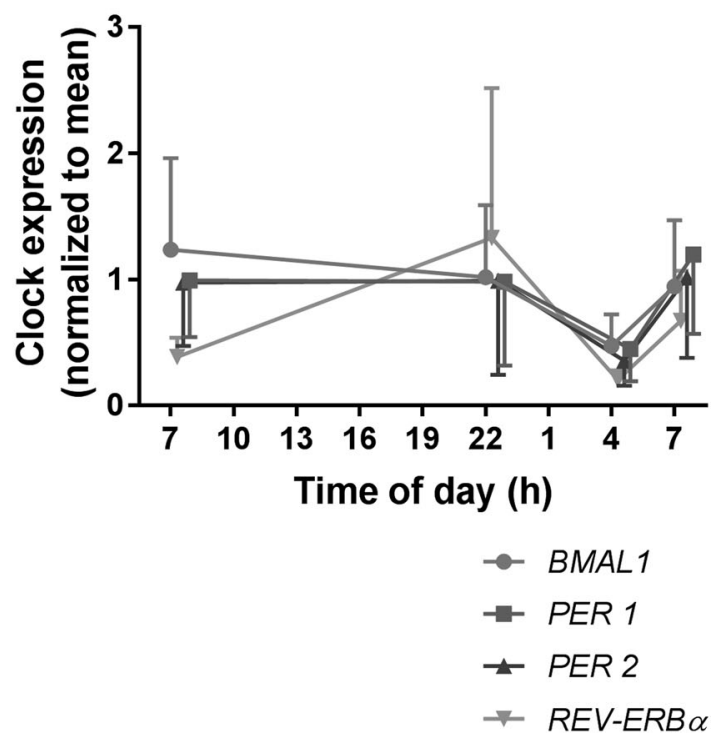

(sleeping). The mRNA expression levels were measured at 07:00, 22:00, 04:00, and 07:00 h during the 24-h observation period. Melatonin or placebo were given orally to the tetraplegia group every night at 22:00 $\mathrm{h}$ for four continuous days before blood sampling. The ablebodied males slept (from 23:00 to 07:00 h) or were kept awake during the 24-h observation period

On the other hand increased clock-gene mRNA expression levels in pathological conditions have been reported, e.g., a study found increased mRNA Bmall expression levels in prostate cancer cells [21]. Furthermore, these authors also reported that melatonin supplementation reversed and normalized the expression levels [21], i.e., similar to our findings showing a shift in the peak expression closer to melatonin supplementation. An increase in clock gene mRNA expression could be explained by melatonin receptor hypersensitivity in tetraplegia. For example, hypersensitive receptors in various organs after a SCI are recognized as parts of the mechanism behind vascular autonomic dysreflexia and changes of bladder function [22, 23]. 
a)

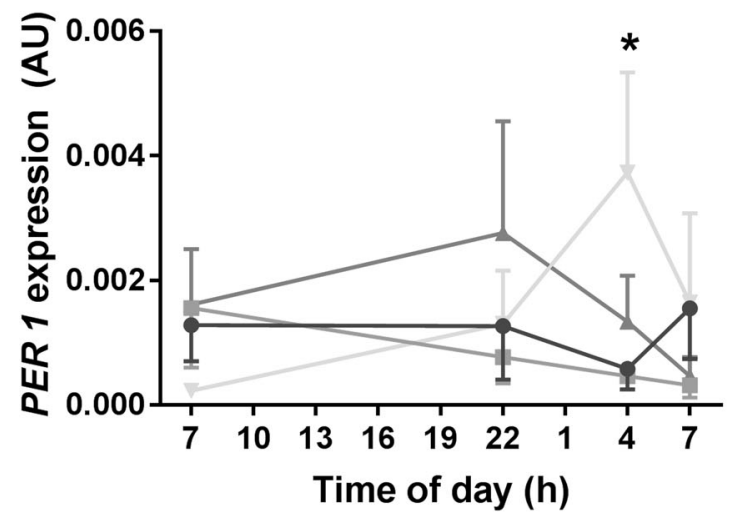

c)

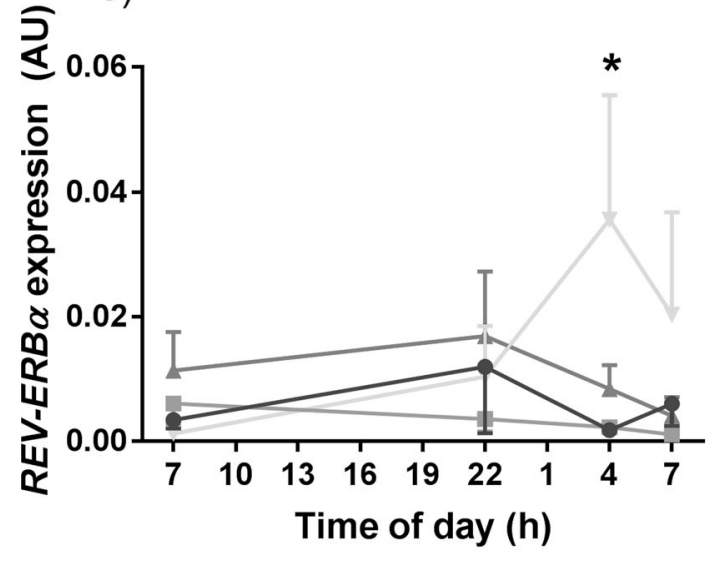

Fig. 4 Comparison of genes among groups, mRNA expression levels of the clock genes in PBMCs during the 24-h observation period. Values are means $( \pm$ SEM). Gene expression was calculated using the $2^{-\Delta \Delta \mathrm{Ct}}$ methods and presented as arbitrary units (AU). a Per 1 ; b Per 2 ; c Rev-Erbo, and d Bmall. The mRNA expression levels were

Our findings with large inter-individual variation in the mRNA expression levels may mirror the heterogeneity of the SCI among the study participants and the complex feedback system of peripheral oscillators in humans [24]. Regulators other than melatonin, e.g., food and social activities, may also affect peripheral clock genes differently in subjects with SCI compared with able-bodied. Disruption of rhythms has been shown to lead to a variety of conditions including sleeping-disorders, depression, and cancer [25], conditions found to be more frequent in SCI [25-29]. A dysregulated peripheral clock in tetraplegia may be a contributing factor of the increased risk of such disorders and indeed there is evidence that the use of Circadin (melatonin) over prolonged period of time has a positive effect on sleep

b)

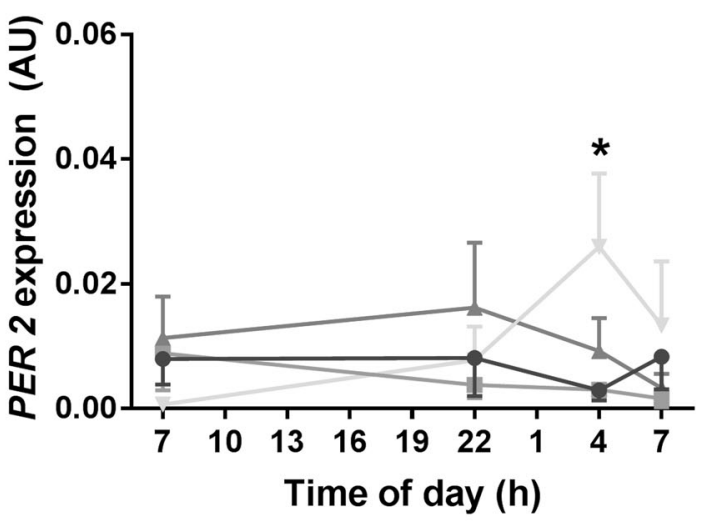

d)

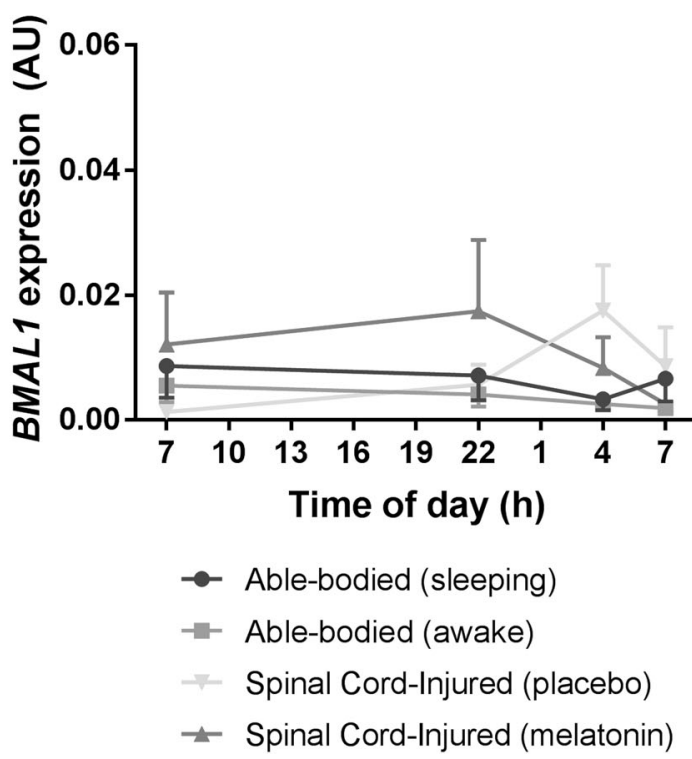

measured at 07:00, 22:00, 04:00, and 07:00 h during the 24-h observation period. Melatonin or placebo were given orally to the tetraplegia group every night at 22:00 h for four continuous days before blood sampling. The able-bodied males slept (from 23:00 to 07:00 h) or were kept awake during the 24 -h observation period

related disturbances in elderly people with low melatonin levels [30].

Despite the low number of participants, our study was robustly designed and the study subjects were carefully monitored under standardized conditions during the 24-h study period. The washout time for plasma or brain drug levels is not necessarily the same as for the downstream effects on receptor pathways and gene translation and/or transcription. Our study design was not designed to observe these downstream effects. In-hospital-induced stress can modify clock gene expressions [31], but this effect should have been minimized by the double blinded and randomized cross-over design. Moreover, the tetraplegic group was rather uniform as only males were included and they all had 
a complete and stable, long-standing injury ( $>3$ years). Importantly, the tetraplegic and able-bodied subjects were matched regarding gender, age, and BMI.

\section{Conclusions}

To our knowledge this is the first study to describe disrupted 24-h clock gene expressions PBMCs in males with tetraplegia. Our main result was that tetraplegic males receiving placebo have increased Perl, Per2, and Rev-Erb $\alpha$ mRNA expression levels in the early morning compared with ablebodied. Specifically, melatonin supplementation for 4 days changed mRNA expression profile in PBMCs in tetraplegia by shifting the peak expression toward the time point of melatonin supplementation. More studies in larger SCI patient cohorts are needed to map the regulatory function of melatonin on peripheral clock genes in various organs.

Acknowledgements We are grateful to all the subjects who participated in the study. We are also grateful for the help provided by Hilde Einerkjær, Marianne M. Voll, and Gro E. Paulsboe at the Laboratory at Sunnaas Rehabilitation Hospital. Financial support was provided from the Throne Holst Foundation. CB and EF were also supported by the University of Ferrara (FAR2016).

Authors contributions EK was responsible for designing the study, collecting data and interpreting them, and writing the paper. EF was responsible for analyzing data and interpreting them, and writing the paper. MS was responsible for interpreting data and writing the paper. $\mathrm{AD}$ was responsible for designing the study, interpreting data, and writing the paper. PMS was responsible for designing the study, interpreting data, and writing the paper. MCM was responsible for analyzing data and writing the paper. GS was responsible for interpreting data and writing the paper. $\mathrm{B} \emptyset$ was responsible for analyzing data and interpreting them and writing the paper. $\mathrm{CB}$ was responsible for analyzing data and interpreting them and writing the paper. POI was responsible for designing the study, interpreting data, and writing the paper.

\section{Compliance with ethical standards}

Statements of ethics We certify that all applicable institutional and governmental regulations concerning the ethical use of human volunteers were followed during the course of this research.

Conflict of interest The authors declare that they have no conflicts of interest.

\section{References}

1. Reppert SM, Weaver DR. Molecular analysis of mammalian circadian rhythms. Ann Rev Physiol. 2001;63:647-76.

2. Mohawk JA, Green CB, Takahashi JS. Central and peripheral circadian clocks in mammals. Ann Rev Neurosci. 2012; 35:445-62.

3. Bjarnason GA, Jordan R. Rhythms in human gastrointestinal mucosa and skin. Chronobiol Int. 2002;19:129-40.
4. Takata M, Burioka N, Ohdo S, Takane H, Terazono H, Miyata M, et al. Daily expression of mRNAs for the mammalian Clock genes Per2 and clock in mouse suprachiasmatic nuclei and liver and human peripheral blood mononuclear cells. Jpn J Pharmacol. 2002;90:263-9.

5. Boivin DB, James FO, Wu A, Cho-Park PF, Xiong H, Sun ZS. Circadian clock genes oscillate in human peripheral blood mononuclear cells. Blood. 2003;102:4143-5.

6. Kusanagi H, Hida A, Satoh K, Echizenya M, Shimizu T, Pendergast JS, et al. Expression profiles of 10 circadian clock genes in human peripheral blood mononuclear cells. Neurosci Res. 2008;61:136-42.

7. Kostovski E, Dahm AE, Mowinckel MC, Stranda A, Skretting G, Osterud B, et al. Circadian rhythms of hemostatic factors in tetraplegia: a double-blind, randomized, placebo-controlled crossover study of melatonin. Spinal Cord. 2015;53:285-90.

8. Verheggen RJ, Jones H, Nyakayiru J, Thompson A, Groothuis JT, Atkinson $\mathrm{G}$, et al. Complete absence of evening melatonin increase in tetraplegics. FASEB J. 2012;26:3059-64.

9. Zeitzer JM, Ayas NT, Shea SA, Brown R, Czeisler CA. Absence of detectable melatonin and preservation of cortisol and thyrotropin rhythms in tetraplegia. J Clin Endocrinol Metab. 2000; 85:2189-96.

10. James FO, Boivin DB, Charbonneau S, Belanger V, Cermakian N. Expression of clock genes in human peripheral blood mononuclear cells throughout the sleep/wake and circadian cycles. Chronobiol Int. 2007;24:1009-34.

11. Grivas TB, Savvidou OD. Melatonin the "light of night" in human biology and adolescent idiopathic scoliosis. Scoliosis. 2007;2:6.

12. Iversen PO, Dahm A, Skretting G, Mowinckel MC, Stranda A, Osterud B, et al. Reduced peak, but no diurnal variation, in thrombin generation upon melatonin supplementation in tetraplegia. A randomised, placebo-controlled study. Thromb Haem. 2015;114:964-8.

13. Livak KJ, Schmittgen TD. Analysis of relative gene expression data using real-time quantitative PCR and the $2^{-\Delta \Delta C T}$ method. Methods. 2001;25:402-8.

14. Kirshblum SC, Burns SP, Biering-Sorensen F, Donovan W, Graves DE, Jha A, et al. International standards for neurological classification of spinal cord injury. J Spinal Cord Med. 2011; 34:535-46.

15. Gibson AE, Buchholz AC, Martin Ginis KA. C-Reactive protein in adults with chronic spinal cord injury: increased chronic inflammation in tetraplegia vs paraplegia. Spinal Cord. 2008; 46:616-21.

16. Acuna-Castroviejo D, Rahim I, Acuna-Fernandez C, FernandezOrtiz M, Solera-Marin J, Sayed RKA, et al. Melatonin, clock genes and mitochondria in sepsis. Cell Mol Life Sci. 2017; 74:3965-87.

17. Russcher M, Chaves I, Lech K, Koch BC, Nagtegaal JE, Dorsman $\mathrm{KF}$, et al. An observational study on disturbed peripheral circadian rhythms in hemodialysis patients. Chronobiol Int. 2015; 32:848-57.

18. Rana S, Munawar M, Shahid A, Malik M, Ullah H, Fatima W, et al. Deregulated expression of circadian clock and clockcontrolled cell cycle genes in chronic lymphocytic leukemia. Mol Biol Rep. 2014;41:95-103.

19. Kavcic P, Rojc B, Dolenc-Groselj L, Claustrat B, Fujs K, Poljak $\mathrm{M}$. The impact of sleep deprivation and nighttime light exposure on clock gene expression in humans. Croat Med J. 2011; 52:594-603.

20. Ackermann K, Plomp R, Lao O, Middleton B, Revell VL, Skene $\mathrm{DJ}$, et al. Effect of sleep deprivation on rhythms of clock gene expression and melatonin in humans. Chronobiol Int. 2013; 30:901-9. 
21. Jung-Hynes B, Huang W, Reiter RJ, Ahmad N. Melatonin resynchronizes dysregulated circadian rhythm circuitry in human prostate cancer cells. J Pineal Res. 2010;49:60-68.

22. Garstang SV, Miller-Smith SA. Autonomic nervous system dysfunction after spinal cord injury. Phys Med Rehabil Clin N Am. 2007;18:275-96.

23. Popa C, Popa F, Grigorean VT, Onose G, Sandu AM, Popescu M, et al. Vascular dysfunctions following spinal cord injury. J Med Life. 2010;3:275-85.

24. Grimaldi B, Nakahata Y, Kaluzova M, Masubuchi S, SassoneCorsi P. Chromatin remodeling, metabolism and circadian clocks: the interplay of CLOCK and SIRT1. Int J Biochem \& Cell Biol. 2009;41:81-86.

25. Scheer FA, Zeitzer JM, Ayas NT, Brown R, Czeisler CA, Shea SA. Reduced sleep efficiency in cervical spinal cord injury; association with abolished night time melatonin secretion. Spinal Cord. 2006;44:78-81.

26. Biering-Sorensen F, Biering-Sorensen M. Sleep disturbances in the spinal cord injured: an epidemiological questionnaire investigation, including a normal population. Spinal Cord. 2001;39:505-13.

27. Jakimovska VM, Kostovski E, Biering-Sorensen F, Lidal IB. Psychological distress and user experiences with health care provision in persons living with spinal cord injury for more than 20 years. Spinal Cord. 2017;55:864-9.

28. Groah SL, Weitzenkamp DA, Lammertse DP, Whiteneck GG, Lezotte DC, Hamman RF. Excess risk of bladder cancer in spinal cord injury: evidence for an association between indwelling catheter use and bladder cancer. Arch Phys Med Rehabil. 2002;83:346-51.

29. Slattery ML. Physical activity and colorectal cancer. Sports Med. 2004;34:239-52.

30. Lemoine P, Zisapel N. Prolonged-release formulation of melatonin (Circadin) for the treatment of insomnia. Expert Opin Pharmacother. 2012;13:895-905.

31. Azama T, Yano M, Oishi K, Kadota K, Hyun K, Tokura H, et al. Altered expression profiles of clock genes hPerl and hPer 2 in peripheral blood mononuclear cells of cancer patients undergoing surgery. Life Sci. 2007;80:1100-8. 